\title{
Creation artificial soil-ground at gardening of objects of landscape architecture in Western Siberia
}

\author{
Dmitry Eremin ${ }^{1, *}$, Diana Eremina ${ }^{1}$ \\ ${ }^{1}$ The State Agrarian University of Northern Zauralye, Republic Street, 7, Tyumen, 625003, Russia
}

\begin{abstract}
Now for creation of a fertile layer usually use peat-sandy mixes in various parities, which initially do not approach for long-term development of grasses. It leads to that the grassy cover on slopes of roads, city lawns within 2-3 years perishes and is replaced natural by weeds with the vegetation which is not forming strong of sod. The carried out analysis of granulometric structure of soils on which perennial grasses grow, has shown, that as a part of artificial soil the clay containing oozy particles $(<0.001 \mathrm{~mm})$ should be an obligatory component. The developed optimising model has shown, that at observance of necessary conditions probably reception artificial soil of middle-loamy granulometric composition possessing optimum physical and agrochemical properties, necessary for long growth of perennial grassy vegetation. As local components it is necessary to use clay, small sand, peat in the parities received at calculation of optimising model. The parity between sand, peat and clay should make 1:2:7. For effect prevention acidification from peat and improvement of agrochemical properties it is necessary to add on 100 $\mathrm{kg}$ of a mix of $0.5 \mathrm{~kg}$ complex fertilize and $0.2 \mathrm{~kg}$ of a dolomitic flour that will provide nutrients to plants while in artificial soil it's own microflora will not start to work.
\end{abstract}

\section{Introduction}

Western Siberia has been mastered already in the end of 16 centuries. However active building of cities has begun only in 50th years of last century. Therefore they by right are considered young and modern from the point of view of architecture. Now the townplanning of Western Siberia has faced the major problem - creation of the fertile soil necessary for gardening of city territories.

In the city territories which are taken away for lawns and parks, as a rule, the top fertile layer is absent in most cases, on sites sandy or clay breeds are bared. There is a lot of a construction waste and other production wastes.

At creation of green plantings on city objects of landscape architecture, especially in the territories broken by anthropogenous activity, it is necessary to create conditions for normal functioning of vegetation. With that end in view it is necessary to generate cultural root

\footnotetext{
* Corresponding author: soil-tyumen@yandex.ru
} 
layer of soil, capable to satisfy requirement of plants for nutrition elements, oxygen and water throughout decades.

On modern scientific representations and on the basis of foreign and domestic experience of landscape gardening building cultural root layer the soil cover under lawns should be thickness not less than $0.5 \mathrm{~m}$ and consist of the several horizons harmoniously interconnected among themselves. A necessary condition is the close physical and chemical interrelation of horizons of a soil cover.

One of the main reasons of deficiency of fertile soils is the severe climate prevent natural soil-forming process. Soils with well-developed humus horizon which could be used for dumping lawns, flowerbeds and parks are actively used now in agriculture. Removal of a fertile layer from them is forbidden, therefore to gardening of cities apply artificial soil-ground. At their creation many indicators, except for density usually are not considered. Discrepancy of physico-mechanical and chemical properties of artificial soilground leads to death of lawns and wood plantings. Therefore at creation of an artificial fertile layer it is necessary to consider climatic conditions and biological features of plants which will be used for gardening of city territories.

In Western Siberia at creation of a fertile layer urbanozem the peat-sandy mix in a volume parity of $70-80 \%$ of peat and $20-30 \%$ of sand is usually used. Visually the mix looks presentably enough, is similar to a fertile layer of the earth and should approach for all plants growing on it. Long-term supervision over a condition of lawns in the Siberian cities have shown, that annually perishes to $30 \%$ of the area of lawns, and $50 \%$ are characterised by very weak projective covering. The detailed analysis of a condition of city lawns has given the chance to establish absence normally developed of sod which is the important part of a grassy cover. The reason of it is initially incorrect approach to formation artificial soil-ground on which the grassy vegetation would feel excellently.

The purpose of researches. Development of componential structure artificial soil-ground on the basis of the analysis of fertility of chernozem soils of Western Siberia, providing favorable growth of perennial grasses

\section{Materials and Methods}

Researches on influence artificial почвогрунтов on conditions of growth of lawns and other green plantings were spent at the State agrarian university of Northern Zauralye. As object lawns, beds and parks of Tyumen have been chosen. For formation optimum artificial soil-ground leached chernozem as the fertility standard has been chosen. The granulometric composition humus a layer and spreading breed of chernozem has been defined on laser unit Analisette-22. Using the optimizing computer model developed on chair mathematicians and computer science it has been made multicomponent artificial soilground of local raw materials (clay, peat, sand, fertilizers).

\section{Results and discussion}

Has historically developed, that the perennial grassy vegetation grew and developed on soils heavy granulometric composition, concerning to loam or to clay versions. Our researches of virgin chernozems of Western Siberia have proved that optimum for grasses will be middle-loamy granulometric composition (Figure 1). On such versions of chernozems the phytomass of grassy plants reaches 15-18 tons per hectare; it is strongly marked well developed sod. On sandy chernozem the biomass of a grass is much less - 710 tons. The reason of it is the adverse nutritious and water modes formed on chernozems light granulometric structure. Chernozem or chestnut soils are characterized by the big 
moisture capacity, water penetration and water elevating ability that in a zone of insufficient humidifying will be the main indicator for development of perennial grasses $[1,2]$. The conservation of soil moisture helps also by the grassy vegetation forming powerful of sod through which water free passes deep into soils and by that does not flow down on a surface. Sod prevents the evaporation, creating effect of mulch. Therefore for favorable development of grassy vegetation on artificial soil-ground it is necessary to achieve, first of all, the prompt formation of sod.

Common in Russia, peat-sand mixture can hold enough water because the moisture content of certain types of peat can reach $1000 \%$ of its volume [3]. Sand also creates the conditions for good water permeability. However, when drying peat for a long time loses its water-holding capacity, it becomes lighter than water and easily removed during snow melt or during heavy rains. Another negative point - peat-sand mixture hasn't a water-lifting ability due to the lack of capillary network. It is present only in the soil with a high content of silt particles. For Western Siberian peat-sand mixtures have another drawback - they have a very low conductivity. In severe winter conditions the soil under the peat layer quickly frozen, but the spring thaw is very slow. This leads to the formation of the shallow root system of perennial grasses and premature death as the result of dehydration in the summer.

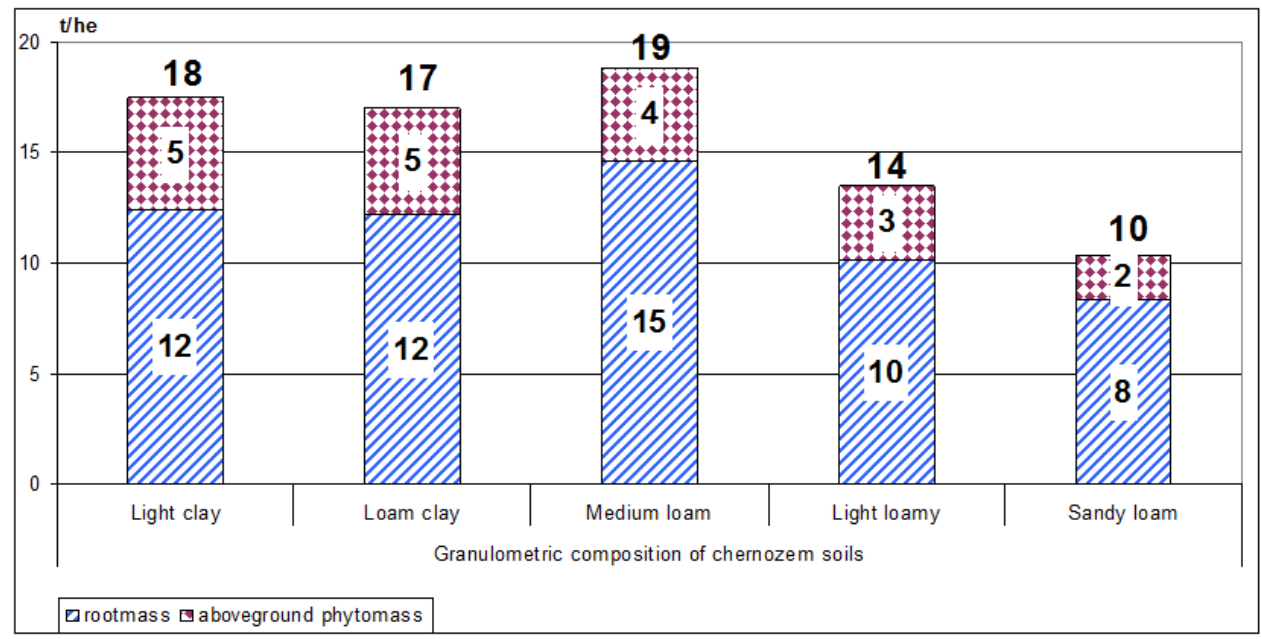

Fig. 1. Phytomass of perennial grasses on chernozem soils different granulometric composition, t/hectares.

A further feature of chernozem soils of heavy granulometric composition is the high absorption capacity (cation exchange capacity), which is responsible for the retention of nutrients in the upper layer, preventing their premature washout when rain or snowmelt. The most important physico-chemical (exchange) and chemical absorption ability - they keep the phosphorus and potassium in the soil, making it available to plants. Chernozem soils initially have a high absorption capacity up to $40 \mathrm{mEq} / 100 \mathrm{~g}$ soil, while the sand is characterized by very low values - no more than $10-12 \mathrm{mEq} / 100 \mathrm{~g}$ of soil [4].

The reason for this is the presence in soil of silty particles with a size less than 0.001 $\mathrm{mm}$, the colloids, the core of which is the active humus. However, a humic substance in the peat is inert, since they were formed centuries ago. Therefore the problem of nutrient status of peat and sand mixtures will not be solved by the use of mineral fertilizers, because they will be washed in the first year. For the retention of phosphorus it is necessary to have a sufficient number of calcium cations in the soils mixture, constantly replenished by calcium carbonate, which initially is not in the sand and the peat. 
To solve the optimal fertile soils for perennial grasses it is necessary to conduct a detailed analysis of the granulometric composition of chernozem. Figure 2 presents the diagram of distribution of the fractions of elementary soil particles of leached chernozem as the most fertile soil in West Siberia.

On the average on sand fraction accounts for up to $25 \%$ of set of all particles. It should be noted that this fraction is represented by fine sand $(0.25-0.05 \mathrm{~mm})$. It is a characteristic feature of soils of the Siberian region [5].

In the nature there are the chernozems generated on loess where sand practically is not presented, however these chernozems are characterised by the lowered water penetration, which in the conditions of Siberia can lead to occurrence of superficial washout. At $30 \%$ accounts for a fraction of a coarse dust and silt - it's a combination gives the chance formations favorable granulometric composition. It is necessary to notice, that in the Tyumen area, especially in its northern areas often use dust the sand which sizes correspond to a coarse dust [3].

However, they do not approach for creation soil-ground as their mineralogical structure is presented by the mainly strongly crushed quartz which does not comprise some nutrients and cannot form a basis for primary structurization.

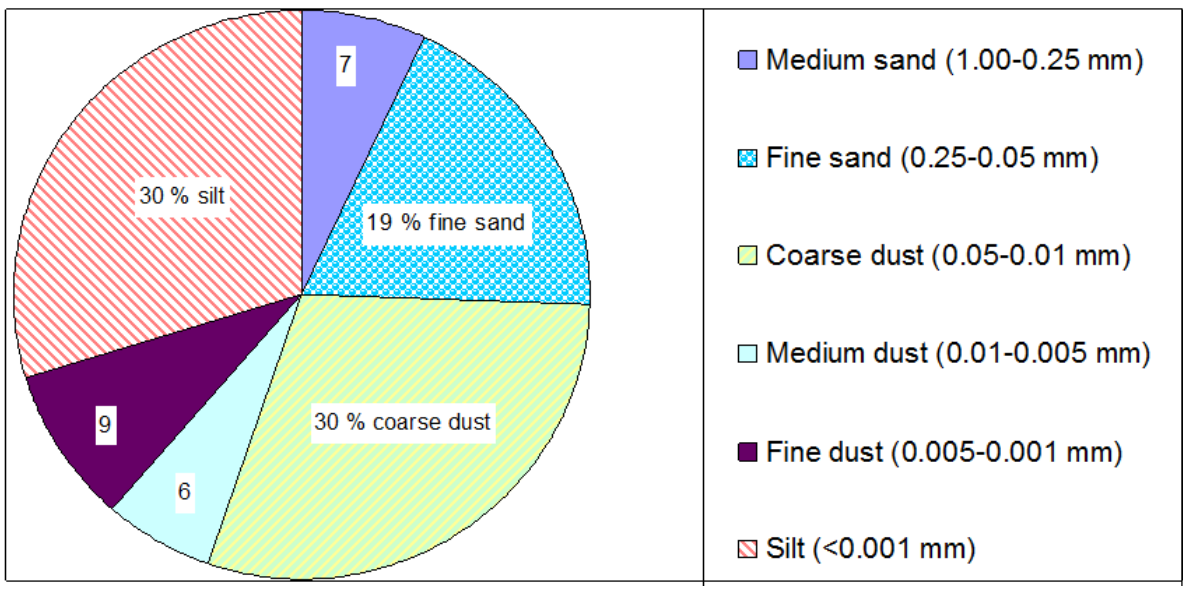

Fig. 2. Granulometric composition of the humus layer of leached chernozem in the forest steppe zone of Zauralye.

The lake sapropel which stocks in the country are huge can be a source of silt particles for creation artificial soil-ground. Also the clay withdrawn at building or working out of open-cast mines can appear very good raw materials. In any case, the detailed analysis of granulometric composition is necessary for inclusion in a settlement part of model. At clay use as bases of a mineral matrix, it is possible to refuse separate addition of the basic fractions of elementary soil particles as usually it initially possesses rather favorable granulometric composition (Figure 3). 


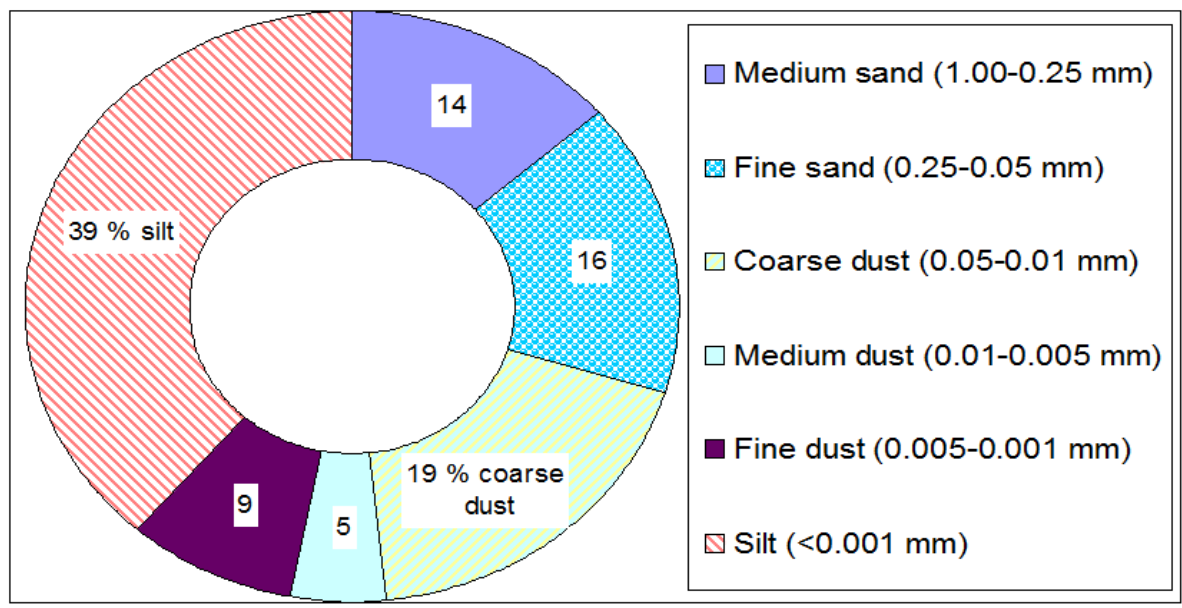

Fig. 3. Granulometric composition of underlying rocks in the South of the Tyumen region, the depth of the selection of 5 meters.

At use of clay as a component at drawing up soil-ground it is necessary to check up it on presence of water-soluble salts which can have harmful influence on development of grassy vegetation. For this reason we do not recommend to replace clay with sludge deposits which have remained at oil extracting, despite rather favorable granulometric composition [6].

If as a basis there will be clay extracted from depth of 1-2 meters it will relieve us of entering of a calcium carbonate as in a forest-steppe zone of Zauralye it meets practically everywhere on this depth. Otherwise - the calcium carbonate is necessary for entering in the form of a chalk, lime or dolomitic flour.

As a result of the analysis of elements of fertility of chernozem we had been developed optimising model of structure artificial soil-ground, possessing properties chernozem soils and favorable for development on it seeded perennial grasses. As a mineral matrix we used the sand taken from open-cast mine, near the city of Tyumen; clay - from a place of construction of many-storeyed houses; peat.

Before mixing clay was dried, crushed and sifted through a sieve with diameter of apertures $2 \mathrm{~mm}$. Use of not crushed clay does not give uniform hashing with peat. The parity between sand, peat and clay has made 1:2:7 accordingly. After hashing in a concrete mixer on $100 \mathrm{~kg}$ of a mix $0.5 \mathrm{~kg}$ complex fertilisers and $0.2 \mathrm{~kg}$ of a dolomitic flour have been added. The experimental sample of soil-ground created by us was characterised medium loam by structure, the optimum acid-alkaline characteristic ( $\mathrm{pH} 6.5$ units) and the balanced nutrients for grassy plants.

\section{Conclusion}

Use of a peat-sandy mix as creation of a fertile layer at formation of lawns or flowerbeds in the conditions of Western Siberia is unacceptable, as on agrochemical and to water-physical properties it cannot provide normal development of perennial grasses after sowing. The peat-sandy mix cannot be favorable for long growth of perennial grasses because of unsatisfactory physico-mechanical and agrochemical properties.

For formation optimum for seeded grasses artificial soil-ground as the standard it is necessary to use the characteristic of fertility of local soils on which grassy plants initially grow. As the integral components it is possible to apply clay, small sand, peat in the parities received at calculation of optimising model. Made soil-ground in corresponding proportions 
it is characterised favorable agrochemical and the water-physical properties close on parameters to chernozem soil.

\section{References}

1. G.S. Bazykina, S.V. Ovechkin, Eurasian Soil Science 49, 437-449 (2016) DOI: $10.1134 / \mathrm{S} 1064229316040025$

2. D.I. Eremin, Eurasian Soil Science 49, 538-545 (2016) DOI: $10.1134 / \mathrm{S} 1064229316050033$

3. A.V. Iglovicov, Procedia Engineering 165, 800-805 (2016)

4. I.G. Asylbaev, I.K. Khabirov, Eurasian Soil Science 49, 24-32 (2016) DOI: $10.1134 / \mathrm{S} 1064229316010026$

5. D.I. Eremin, D.V. Eremina, Procedia Engineering 165, 788-793 (2016)

6. O.Z. Eremchenko, Russian journal of ecology 38, 16-21 (2007) DOI: $10.1134 / \mathrm{S} 1067413607010031$ 